\title{
La responsabilidad ética
}

\author{
Miguel ÁNGEL POLO SANTILLÁN* \\ Universidad Nacional Mayor de San Marcos (Perú) \\ mpolos1@unmsm.edu.pe
}

\begin{abstract}
Resumen
El artículo es una exploración mayéutica de la responsabilidad, pues mediante preguntas trata de explorar este tema. Inicia el autor desde las distintas maneras de dar respuesta, pues de ahí viene la palabra responsabilidad, ellas revelan nuestra pertenencia a la humanidad y a la naturaleza. Por eso, los lazos, los compromisos, las obligaciones vividas es lo que nos hace sentir responsables. La responsabilidad sentida como obligación o coerción externa solo refleja la ontología moderna que ha separado al individuo de todo y de todos, por lo que prefiere la libertad a la responsabilidad. Se requiere pensar de otro modo la responsabilidad, pues este aislacionismo individualista no solo perjudica al propio individuo, sino a la humanidad y al planeta.
\end{abstract}

Palabras clave: Responsabilidad, ética, interdependencia, cuidado, empatía, política.

\section{The ethical responsibility}

\begin{abstract}
This paper is a maieutic exploration of responsibility, since by means of questions it tries to explore this topic. The author starts from the different ways of giving an answer, because that is where the word responsibility comes from, they reveal our belonging to humanity and nature. Therefore, the bonds, the commitments, the lived obligations are what make us feel responsible. The responsibility felt as an obligation or external coercion just reflects the modern ontology that has separated the individual from everything and everyone, so he prefers freedom to responsibility. It is necessary to think responsibility in another way, because this individualistic isolationism not only harms the individual himself, but also humanity and the planet.
\end{abstract}

Key words: Responsibility, ethics, interdependence, care, empathy, politics.

\footnotetext{
* Doctor en Filosofía. Miembro del Instituto de Investigaciones Humanísticas de la UNMSM, de la Sociedad Peruana de Filosofía, de la Asociación Peruana de Ética y Filosofía Política (ASPEFIP) y la Asociación Iberoamericana de Filosofía Práctica. Entre sus principales obras están: Ética y crisis moral (1996), Ética, modo de vida, comunidad y ecología (2001), La morada del hombre. Ensayos sobre la vida ética (2004), Los lenguajes de la ética. Un panorama de las éticas contemporáneas (2006), Ética y Razón Práctica (2009) y Ética. Definiciones y teorias (2013).
} 
INTRODUCCIÓN

Este artículo es una indagación sobre la responsabilidad en sus distintos aspectos. $\mathrm{Y}$ al tener múltiples facetas, resulta no una realidad simple, sino compleja. Por eso, este viaje de exploración no ha sido solo intelectual, sino sobre la vida humana misma. ¿Cómo pensar en la "responsabilidad" sin pensar en la condición humana actual, mejor dicho, sin responsabilizarnos (al pensar) de dicha condición? Aunque el camino ha sido básicamente filosófico, es decir, antropológico y ético, sin embargo, no he querido encerrar la responsabilidad en una teoría, sino dejar que ella vaya mostrando su ser. Ese despliegue ha hecho aparecer temas como los siguientes: la acción, la red de relaciones vitales, las creencias y los compromisos, la libertad y el futuro, el poder y la política, la ética mundial y la educación del sentimiento, las instituciones, etc. Todos estos temas centrados por nuestra relación con el otro. Y desde ahí hemos postulado una responsabilidad ética identificada con el cuidado de la vida. Con ello llegamos al centro de la rueda, que es la ontología que presupone la idea de responsabilidad, sobre cómo nos vemos y sentimos con respecto al otro y a lo otro.

Mi camino ha sido el mayéutico, preguntándome y respondiéndome, a veces en la claridad del campo, otras en la espesura del bosque, a veces caminando pesadamente por el desierto sin destino claro, otras sentado bebiendo agua fresca del río. Y como dicen los sabios, los frutos no han estado al final, sino en el camino mismo. Estas son mis reflexiones.

\section{1. ¿QUÉ SIGNIFICA “RESPONSABILIDAD”?}

El término responsabilidad, que "aparece tardíamente en la ética" (Bilbeny, 2012: 194), viene del latín responsum, "responder". Y ese significado se ha conservado en la mayoría de los idiomas modernos, como por ejemplo en alemán, responsabilidad se dice Verantwortung, que viene de Antwort, respuesta. Y muchas son las razones y maneras en las que podemos responder. Podemos clasificarlas en tres formas de responsabilidad:

a) La responsabilidad ética: como seres humanos percibimos y somos conscientes, en distinto grado, de la existencia y sus condiciones. Y ante tal hecho, damos respuesta, sea con acciones u omisiones. Así, si nos damos cuenta del deterioro del planeta, eso mismo nos exige una respuesta personal y colectiva, por ejemplo, disminuyendo nuestra huella ecológica dejando de comprar productos que sabemos dañan al medio ambiente o quizá dejar de conducir el automóvil determinados días de la semana. Esta 
responsabilidad ética surge de nuestro mero hecho de existir y ser conscientes del mundo en el que vivimos.

b) La responsabilidad moral: es la respuesta que debemos dar por las normas morales que permiten la convivencia humana. En este caso es el deber el criterio de la responsabilidad. Por ejemplo, cuando un joven cristiano se niega a ir a la guerra, porque ha interiorizado la norma de su comunidad religiosa, el "no matarás" o "el amor al prójimo". Se puede decir que es responsable ante su conciencia o ante su comunidad o ante Dios. El cumplimiento de los Derechos Humanos, como declaración, estaría en este nivel.

c) La responsabilidad legal: es la respuesta que damos ante las leyes de un país o leyes internacionales. Somos responsables como ciudadanos o por la actividad o por la función, estamos dentro de un marco legal ante el cual debemos responder. Por eso podemos decir que los choferes son irresponsables si se pasan la luz roja o si el funcionario público acepta coimas de empresarios para ganar una licitación o si no cedemos el asiento a las personas que les corresponde los asientos preferenciales. Y cuando los Derechos Humanos son asumidos por los estados en Tratados Internacionales y plasmados en sus constituciones y legislaciones, también en este caso los ciudadanos y gobernantes tienen responsabilidad legal.

Ser responsable manifiesta nuestra pertinencia al mundo, a una comunidad y a la humanidad. La responsabilidad me revela que estoy en el mundo con otros, comparto el mundo con ellos y desde esa relación se generan lazos, compromisos, obligaciones. La clave de la responsabilidad, entonces, es la respuesta. Responder, ¿de qué?, ¿por qué?, ¿ante quién o quiénes? Cuestiones que procuraremos responder ${ }^{1}$.

El término "responsabilidad" tiene una fuerte carga deontológica (sentidos b y c), es decir, que cuando usamos esta palabra la asociamos con deberes, obligaciones que tenemos. "Tienes que ser responsable" le decimos a nuestros hijos, con lo cual queremos decir que deben cumplir

\footnotetext{
1 Si los filósofos responden a preguntas, entonces ¿`son responsable? Esto puede tener dos respuestas. La primera exonera a la filosofía de responsabilidad, porque las preguntas filosóficas son abstractas. El filósofo se pregunta: “¿Qué es el hombre? ¿Qué significa ser feliz? ¿Por qué debemos ser responsables?”, y sus respuestas no están pensadas para darlas a alguien en específico, sino en la argumentación racional que se mueve en el plano de las ideas. La otra posición sostendría que hay responsabilidad en el pensar mismo, no solo por lo pensado, sino por la exigencia misma de pensar que surgen del tiempo que se vive. Nosotros asumimos esa segunda versión.
} 
con sus obligaciones. Y desde este sentido restringido, quien obra responsablemente no se siente necesariamente libre ${ }^{2}$. Sin embargo, ¿tiene un sentido más amplio que el deontológico? Pensamos que sí, pero desde el punto de vista ético.

\section{2. ¿EN VIRTUD DE QUÉ SOMOS RESPONSABLES?}

¿Qué hace que seamos responsables? Es por nuestra conciencia de la existencia de los otros. El otro se me hace presente lo cual va constituyendo nuestra conciencia que nos convoca a responder. Como pensaba Levinas, la responsabilidad no empieza en mi subjetividad, sino en la presencia del otro que me cuestiona y exige (su sola presencia me dice que no se puede valer solo, que nos necesita, pero a su vez me devuelve la conciencia de mi ser como ser dependiente), podemos añadir que no es posible responder a esa presencia vulnerable sino es por medio del cuidado. La responsabilidad hace de la cura de sí un cuidado por los otros. El otro se presenta en su indigencia, como persona vulnerable, pobre y excluida, pero ante su presencia puedo cerrar la vista, dirigirla a otro lugar para que no me llegue su cuestionamiento. Atreverse a mirar es romper las barreras de la subjetividad, de lo que protege al yo y sus defensas, es decir, es también ser indefenso. Y desde esa mirada atenta permitir que surja el cuidado. La actitud de cuidado misma empieza en esa mirada atenta, para escuchar y aprender a escuchar superando bloqueos subjetivos (experiencias, recuerdos, creencias, etc.). El cuidado se manifiesta ahora como inquietud, el sujeto se siente preocupado por la respuesta. Así abre la puerta a la compasión y a la prudencia. A veces tendrá que pensar sobre lo que debe hacer, otras veces tendrá la prioridad la compasión como respuesta sensible. En síntesis, la responsabilidad no puede ser solo formal, sino que debe manifestarse como sentimiento de responsabilidad.

Sin embargo, hablamos de los otros, por lo que su existencia (que también me incluye, pues soy otro para alguien más) ya presupone una ontología desde donde podemos ser responsables. Ese "desde dónde" puede darse de dos modos:

a) La modernidad cartesiana no solo nos ha diferenciado, sino también separado ontológicamente entre una persona y otra, entre hombres y naturaleza. Y desde ahí la responsabilidad presupone coerción (interior o

2 Como se verá más adelante, el sentido común de las sociedades actuales contrapone libertad y responsabilidad, es decir, somos libres en la medida que tengamos o asumamos menos obligaciones. Así, el crepúsculo del deber (Lipovetsky, 2005) trae consigo una mayor falta de responsabilidad. Por eso se hace necesario pensar en otro sustento suyo. 
exterior), ese es el significado que subyace a la "obligación”, pues quien se siente obligado se siente coaccionado a dar una respuesta. Este sentido subyace a la responsabilidad moral, legal, y está detrás de nuestras formas modernas de sentirnos responsables. Presuponemos culturalmente que estamos separados y desde ahí la responsabilidad es el deber que tenemos por otros distintos a mi propio ser. Y mientras más se afirme esa separación, más nos costará ser responsables. Quizá eso explique por qué al hombre moderno le resulta difícil ser responsable, aunque exige ser libre, lo cual no es otra cosa que afirmar más la separatividad.

b) El otro sentido del "desde dónde" es del reconocimiento de nuestra condición de seres interrelacionados e interdependientes, lo cual no excluye las diferencias, pero no afirma la separatividad ontológica. Mientras que en la ontología cartesiana la responsabilidad surge como coerción, desde la interrelación (o por ella) surge la empatía, fuente de una responsabilidad diferente, manifestada como benevolencia (promover el bien del otro) o como compasión (acción positiva que surge al darme cuenta del sufrimiento del otro). Si nos percibimos y sentimos ligados, eso mismo ya expresa un significado distinto de "obligación", pues recordemos que el término latino ob es "a causa de", "debido a", por lo que "obligación" significaría que "a causa de estar ligado, de estar relacionado, unido", entonces actuamos. La empatía misma ya nos revela ese lazo vital que tenemos con los otros. Y respondemos porque previamente nos sentimos ligados. $\mathrm{Y}$ este es un significado muy diferente a la moral moderna que tiene presupuestos cartesianos.

\section{3. ¿ANTE QUIÉN SOMOS RESPONSABLES?}

Desde esos dos sentidos ontológicos, la responsabilidad será pensada y sentida también de forma diferente. Vamos a centrarnos en el segundo significado. Ahora, ¿ante quién somos responsables? Podemos ser responsables ante nosotros mismos (auto-responsabilidad), la sociedad, la humanidad, la naturaleza y Dios. No se trata de aspectos contrapuestos ni excluyentes necesariamente. La pregunta por el "¿Ante quién soy responsable?” está asociada a la pregunta por el “¿De quién soy responsable?”. Veamos cada uno de ellos.

a) Auto-responsabilidad. En cada acto, en cada proyecto y decisión, vamos siendo, lo cual afecta a los otros seres con los cuales estamos ligados. Así, una vida asumida fragmentadamente no puede ser pensada en términos de auto-responsabilidad. Suscribimos lo que anota Etxeberria al respecto: "Ser responsable ante mí mismo es considerarme responsable del 
hecho mismo de ser, de ser una persona que debe realizarse como persona. La responsabilidad no es así originariamente algo que afecta meramente a los actos y sus consecuencias, sino algo que remite a la globalidad de lo que somos" (2002: 177). Y vamos siendo personas con otras personas dentro de un mundo previo, por lo que decidamos hacer también influirá a otros y al mundo. Y ese sano sentido común es opacado por el presupuesto del yo cartesiano que exige que los otros y el mundo giren en torno a él. Por eso, siempre le resultará difícil ser responsable.

Esta atención a nuestra vida como un todo interrelacionado nos lleva a dar respuestas y con ello darle un significado o sentido a nuestras vidas. Esta llamada a realizar nuestras vidas en medio de otras vidas nos exige una respuesta, la cual debe ser considerada porque afectará (positiva o negativamente) a otros.

En un mundo egocéntrico, solemos pensar la autorrealización como un proyecto individual, solitario, aislado, con lo cual reforzamos los presupuestos de la ontología separatista y fragmentaria. Una mirada no fragmentaria es ver mi vida como un todo interrelacionado, ver mi vida dentro de un todo dinámico, es decir, verme ligado a un contexto de relaciones desde los cuales mi vida adquiere sentido. Estoy compartiendo el mundo con otros y con relación sostenida por la naturaleza. Solo desde la articulación de esas relaciones puedo llenar la vida de sentido y estar dispuesto a responder por las acciones que realizo o por las formas de vivir que tengo.

Esto nos permite evitar posiciones filosóficas que afirman que uno solo puede ser responsable de sí y ante sí mismo. El mismo Nietzsche tenía esa perspectiva, porque pensaba que la "moral del camello" solo obedece las costumbres establecidas, el individuo estaría domesticado para repetir el pasado, anulando su libertad. Esta forma de interpretar la responsabilidad es, como afirma Camps, "reducida a monólogo, sin vigor dialéctico de la respuesta a un sujeto otro" (1990: 57). Si yo solo respondo de y ante mí mismo, eso anularía la responsabilidad misma y convertiría la vida humana en una vida neurótica ${ }^{3}$.

b) Responsabilidad ante la sociedad. Somos responsables ante los otros con los cuales hago mi mundo circundante, ya que mis elecciones y accio-

\footnotetext{
3 Dado que responsabilidad es responder, en este caso un individuo necesitaría fragmentarse y así, un "yo" imparcial, justo, bueno, superior - como se quiera denominar- escucharía a ese yo que decide y actúa. Sin percatarme que ese "yo" superior no es sino una interiorización del yo social. Así, al rechazar a la sociedad y sus costumbres no hacemos sino interiorizarla, persiguiendo una libertad ilusoria.
} 
nes pueden dirigirse a ellos y afectarlos. Esta responsabilidad revela nuestra constitución social. Dentro de esta responsabilidad podemos incluir las siguientes: la responsabilidad jurídica, la responsabilidad social y la responsabilidad religiosa ${ }^{4}$.

La sociedad es un término muy abstracto que puede convertirse en otro "ídolo" más, al cual habría que ofrecerle sacrificios cada cierto tiempo. Mientras nuestra sensibilidad nos muestra otros concretos, un tú que se me presenta y replantea mi mundo y mis verdades. $\mathrm{Y}$ esos encuentros conforman colectividades, comunidades, que tienen o generan diversos lazos de compromisos, hasta el punto de darnos muchas veces identidades a nuestro ser personal". Por eso nos identificamos y somos "ingenieros", "abogados", "médicos", por pertenecer a comunidades profesionales determinadas. Esas comunidades nos exigen o reclaman ciertas conductas o acciones y ante ellas somos o no responsables. No soy ingeniero solo por mis propios medios, sino porque participo y comparto saberes y procedimientos con otros profesionales, y desde ahí se conforman creencias, normas y valores compartidos entre todos los miembros de la comunidad. Esa es la fuente del deber profesional.

c) Responsabilidad ante la humanidad. Si somos responsables de toda la humanidad como piensan Sartre y Jonas, entonces también somos responsables ante toda la humanidad. Por exagerado que pueda sonar este planteamiento, tiene mayor relevancia en nuestros días, porque nuestros destinos cada vez más se muestran interdependientes. En el sistema jurídico internacional se reconocen crímenes contra la humanidad, entonces ¿por qué no pensar en dar respuestas a la humanidad de esos crímenes? De algún modo hay una dimensión en nuestra conciencia de sentir que somos humanos, a pesar de nuestras diferencias, por lo que tendemos a rechazar los maltratos, las torturas y los crímenes que se producen en cualquier parte del mundo.

El otro, ese otro concreto, es un nudo humano, es decir, manifestación de la realidad de la humanidad, aunque sea concreto y diferente de los demás. Por lo que hace recordar que estoy ante una realidad humana a la cual también pertenezco. La mirada que solo se ve a sí misma termina

\footnotetext{
$4 \quad$ En tanto una religión implica miembros, una comunidad de fieles, ahí se interpreta y vive la responsabilidad de un modo. Pero a su vez, esta comunidad está dentro de una sociedad más amplia y organizada ante la cual debe responder por sus acciones. Por lo que el abuso y agresión contra uno de sus miembros no puede considerarse solo como un problema dentro de la propia organización religiosa, sino que es una falta contra un miembro de la sociedad y deben responder por ello en ese nivel.

Más adelante agregaremos que estas actividades colectivas se realizan dentro de instituciones, por lo que ella influye significativamente en nuestras responsabilidades.
} 
por encerrarnos y perdernos de nuestra humanidad compartida. Así, al mirar al otro salgo de mí y me veo ahí, formando parte de la vida de otros, quienes me afectan y yo afecto sus vidas. De ese modo, no me queda otra acción sino una acción atenta, cuidadosa, prudente, responsable.

Quizá habría que decir que no se trata de cargar en nuestros hombros la suerte de la humanidad, sino que ella es una gran red de relaciones en la que estamos sostenidos y esa mirada de la suerte de la humanidad nos hace mirar nuestra cotidianidad de modo diferente. Sabernos y sentirnos como una "gran familia" cuya suerte cada vez está más ligada, puede hacer que nuestra responsabilidad por lo que nos rodea sea una forma de nuestra responsabilidad de y ante la humanidad.

Y aquí, una vez más, la empatía juega un rol importante, en la medida que abre nuevos horizontes para una mirada más abarcadora y una acción más compasiva. Así, la percepción de la hambruna en África o de niños con tuberculosis en el Perú abre la sensibilidad, las que sustentan la responsabilidad. Observar a un ser querido que muere de cáncer nos coloca en una empatía con otros seres que sufren lo mismo, lo que nos dispone a una respuesta. Cada vez más vamos ampliando nuestros horizontes de empatía, porque lo que hoy tiene más sentido es hablar de una responsabilidad de y ante la humanidad.

d) Responsabilidad ante la naturalera. ¿No es exagerado pensar que somos responsables ante la naturaleza? ¿No somos solo responsables de lo que hagamos ante la naturaleza? ¿No implicaría, una vez más, animar a la naturaleza? Muchos pueblos de la humanidad no ven a la naturaleza como materia inerte o una mercancía, sino como realidad viva, animada, que acompaña, ayuda, protege, limita a los seres humanos. Esas relaciones eran generadas por creencias religiosas de diversos tipos, pero también por vivencias místicas de unidad con el todo. Cada vez nos alejamos más de la idea cartesiana de que los animales son simplemente máquinas y que la naturaleza solo es una fuente de materias primas para el bienestar humano. Un sentido y sentimiento de unidad nos vuelve a enlazar con los otros seres no humanos, sean animales, árboles o montañas. No ser responsables con la naturaleza es seguir pensando que los únicos valiosos son los seres humanos y no debemos ninguna respuesta a la "madre tierra".

Sin embargo, cuando asumimos que la vida es una red de relaciones, que soy el producto de lo que es el medio ambiente, la sociedad, la cultura y mis seres queridos inmediatos, pero que asimismo estoy influyendo en ellos, entonces dar respuesta a la naturaleza, la madre tierra, la pachamama, sí tiene sentido. De ese modo, el marco de la fraternidad se abre a otros 
seres no humanos. Para que no parezca poesía, requiere de una nueva sensibilidad, una empatía que vaya más allá de los círculos familiares y amicales.

e) Responsabilidad ante Dios. Las creencias también sostienen la responsabilidad. Y las creencias religiosas nos hacen pensar que la responsabilidad no solo es ante los hombres o ante la naturaleza, sino ante Dios. Quizá sea así, siempre que la idea de Dios no encubra ni delitos contra la humanidad ni otros tipos de prácticas inmorales ${ }^{6}$, es decir, nos haga irresponsables.

Las personas que asumen creencias religiosas, en lo que Weber ha llamado éticas de la convicción, pueden ser responsables en la medida que cuentan con normas vinculantes, más aún fuertemente vinculantes porque su fuente es considerada divina. Ser responsable ante Dios es ser fieles a la enseñanza o a los mandatos que se suponen superiores. Sin embargo, cuando por ser fiel a Dios (mejor sería decir "a mis creencias acerca de Dios") hiero la dignidad del otro, entonces los criterios de mi responsabilidad ya no se pueden someter solo a parámetros religiosos, sino a criterios morales o jurídicos ${ }^{7}$.

Por otro lado, somos responsables ante Dios, pero ¿somos responsables de Dios? ¿No será atrevido pensar que también somos responsables de Dios? Luego de la historia de la idea de Dios en distintas culturas, creo que esto no es atrevido, sino que es una exigencia de cuidado. Una idea de Dios puede matar o dar vida. Por lo que debemos cuidar de Dios, es decir, de la idea de Dios que tengamos. Y en un sentido radicalmente cristiano, cuidar de Dios es cuidar del prójimo.

Mirados en conjunto, todos estos "sujetos" ante los cuales somos responsables no se relacionan con nosotros aislada o separadamente. Visto de una manera más compleja, todos constituyen facetas de la misma experiencia de responsabilidad, por lo que cuidar del medioambiente es una forma de cuidar de los seres humanos y, por qué no, de Dios mismo.

\footnotetext{
6 Nunca está de más recordar el texto evangélico que señala que amar a Dios implica amar al prójimo, al otro que sufre. Ese Dios más cerca del hombre, que no asusta con infiernos, sino que nos hace mirar el mundo de manera más fraterna es el que nos puede ayudar a ser responsables.

Por ejemplo, si mis creencias religiosas dicen que es un pecado la transfusión de sangre y por eso no permito que a mi hija le hagan la transfusión de sangre que necesita para seguir viviendo, entonces deben hacerse presente los mínimos morales logrados históricamente, que nos impide tratar a otros como simple medios, aunque los fines sean asumidos como superiores. Ese es el marco de derechos de los niños. Sin embargo, para evitar la simple imposición, los grupos religiosos deberían dialogar con la sociedad para tratar sobre esos aspectos problemáticos. No cabe duda que ese diálogo franco enriquecería la vida moral de la sociedad.
} 


\section{4. ¿DE QUÉ SOMOS RESPONSABLES?}

En cuanto somos seres "unitotales", tenemos que dar cuenta de lo que somos y de lo que hacemos. Especificando, podemos señalar los siguientes aspectos:

a) Somos responsables de nuestros propios actos. Cada uno es dueño de sus actos, estos afectan y constituyen nuestras vidas particulares y también la vida de los otros. Tenemos que dar respuesta por lo que hacemos, lo que involucra nuestras pretensiones, intenciones, deseos, razones, que nos impulsaron a actuar. La persona que sabiendo la prohibición de conducir en estado de ebriedad lo hace y luego atropella a otra persona, debe responder por lo que ha hecho.

Así, basándonos en Frankena podemos decir que dos son las condiciones de la responsabilidad: i) que el sujeto haya actuado voluntariamente, elegido libremente; ii) que hubiera podido elegir y obrar de otra manera; iii) que lo hiciera efectivamente (1965: 91-94). Estos tres sentidos ya estaban en Kant, quien entendía la responsabilidad a través de la imputación. "Se me pueden imputar, antes que nada, aquellas acciones de las que soy autor, causa libera, es decir, aquellas acciones con las que me autodetermino habiendo tenido además la posibilidad de actuar de otro modo" (Etxeberria, 2002: 178).

b) También somos responsables de nuestras omisiones, acciones "en las que pudiendo hacer lo debido no lo hemos hecho, permitiendo de ese modo que se generen consecuencias malas" (Etxeberria, 2002: 179). El padre que abandona su familia y no mantiene a sus hijos, se puede decir que es responsable de la situación que atraviesa su familia, es decir, que debe responder por ello. Así, la omisión (sea pensada o querida o simplemente olvido del deber), afecta la vida de otras personas.

c) Somos responsables de las consecuencias de nuestras acciones, aspecto relevante para el utilitarismo y Weber. No bastan las acciones realizadas por buenas intenciones, las consecuencias deben ser previstas para que las acciones sean asumidas con mayor responsabilidad. Hay una conciencia más clara que las acciones buenas pueden producir efectos negativos y no queridos, por lo que se debe estar alerta de sus consecuencias. Si el empresario fabrica juguetes con productos tóxicos y solo busca beneficio económico (fabricar juguetes baratos para los niños pobres) debe responder por los efectos que tengan sus productos en manos de los niños.

Asumimos el término utilizado por el librepensador indio Krishnamurti. 
Además, se hayan querido o no las consecuencias, las personas son responsables de ellas, aunque quizá puedan considerarse grados de responsabilidad según la presencia o no de la voluntad libre.

d) Somos responsables también de las exigencias o retos que nos llaman a actuar, a dar una respuesta. Un médico, por el hecho de serlo, tiene exigencias y afrontará retos propios de su condición. Responder a ellos hace a un médico responsable. En este sentido están envueltos no sólo los deberes (como los profesionales en el caso del médico), sino también nuestra condición (ser médico) y la situación que vivimos. Es decir, ser médico implica asumir conocimientos especializados y deberes profesionales. Y la experiencia (profesional) nos exigirá dar respuestas a las situaciones específicas.

e) Jonas (1995) ha vuelto a hacer referencia a la "responsabilidad del hombre por el hombre". Ante el peligro del fin de la existencia de la humanidad, la vida de la humanidad se vuelve un imperativo. Responsables de la humanidad, no solamente presente sino también futura, por las generaciones futuras, las que ahora no existen pero que vendrán. ¿Qué mundo les dejaremos? ¿Con mejores condiciones para afrontar sus retos? ¿Con más problemas que soluciones? ¿Con un sistema social y económico injusto? ¿Con una crisis medioambiental insostenible? Y aunque no hayamos causado las crisis ecológicas ni sociales y aunque no estemos cuando las generaciones futuras nos juzguen, debemos responder por el tipo de mundo que estamos dejando a nuestros descendientes. Así, los grandes males que atraviesa la humanidad "deben ser reparados, independientemente de que puedan serles imputados a alguien" (Camps, 1990: 75). Tenemos que actuar "como si" esas generaciones futuras existieran, pensando que son nuestros contemporáneos, de esa manera se convierten en un criterio moral de nuestra acción. Así, mirarnos desde el futuro también puede ayudarnos a asumir nuestras responsabilidades.

f) Por lo expuesto, la responsabilidad involucra todos los aspectos que generan las acciones: deseos, sentimientos, ideales y pensamientos, acciones y omisiones, contexto en el que vivimos y sujeto que somos. Responsables de la totalidad de lo que somos, especialmente cuando el mundo subjetivo tiende a generar muchos problemas en la vida humana. La responsabilidad se centra mucho en las acciones y omisiones, pero poco en el mundo mental que las generan. ¿Somos responsables de nuestros deseos, odios, apegos, ansiedades, temores y sentimientos en general? ¿O solo son cosas que nos acontecen y que no podemos controlar? La vida 
humana está hecha de mente ${ }^{9}$, por lo que no podemos excluir de ella a la responsabilidad.

Esto nos lleva a decir que existe una gran responsabilidad de la cual poco se habla, es decir, de las creencias, ideas e ideologías económicas, filosóficas, políticas y religiosas. ¿Necesitamos dejarlas para responder auténticamente? No, pero sí ser responsables de ellas, estar atentos a lo que puedan involucrar. No podemos seguir sacrificando la dignidad ni la vida de las personas por la sobrevaloración que le damos a algunas creencias. Esta responsabilidad se expresa como cuidado de o con las creencias, para que estas favorezcan al bienestar y plenitud humana, en lugar de exterminarla.

$¿$ No estamos volviendo a la moral del camello que carga tantas responsabilidades en sus hombros? Camps sostiene, criticando a Sartre, que la responsabilidad absoluta es excesiva y nos lleva al "absoluto inmovilismo", a la "total irresponsabilidad" (1990: 58-60). Después de todo, los humanos no estamos en la capacidad de saber todas las consecuencias que tendrán nuestras acciones, por más que las hagamos pensando en las generaciones futuras. No nos queda sino una acción atenta, cuidadosa y prudente.

Si ser prudente es ya ser responsable, también podremos decir con Gracia (2011), que a la responsabilidad hay que "gestionarla prudentemente", es decir, dependerá del tipo de situación o problema que se trate y de lo que ello implique. De ese modo, no será lo mismo la responsabilidad que deberá asumir el médico que la del político, a pesar de que en determinadas circunstancias sus responsabilidades puedan encontrarse. En la gestión de la responsabilidad el "objeto" será diferente en cada caso, quizá el medio ambiente, la salud o algún bien social.

Basándonos en Rifkin (2010), quien ha estudiado la ampliación de la conciencia empática a través de la historia, podemos decir que, al ampliarse esa conciencia, también el sentimiento de responsabilidad se ha ampliado. Lo cual no significa que debamos cargar con toda la responsabilidad en cada acto, es decir, tener en cuenta todos los factores en cada acto, lo cual sería absurdo o imposible ${ }^{10}$. Pero sí nos llevaría a considerar qué aspectos relevantes se hacen presentes en cada situación, un contexto ante el cual solo cabe estar atentos. Dicho de otro modo, metafísicamente en cada acto se pone en juego la totalidad de lo que somos, pero en sentido práctico

\footnotetext{
9 No existen acciones u omisiones en que la vida mental esté ausente.

10 Sería tan irresponsable solo encerrarnos en una responsabilidad parcial (como querer ser solo un profesional responsable) como sería tan absurdo pretender ser responsables de todo. Un sano curso medio nos enseña a pensar prudentemente en los factores que están en juego cada circunstancia.
} 
tengo que discernir qué hacer en el aquí y ahora. Universalidad y particularidad que no deberían estar divorciadas.

\section{5. ¿EL PODER NECESITA DE LA RESPONSABILIDAD?}

El poder que ha adquirido el ser humano, especialmente en nuestra época, hace necesario pensarlo en términos de responsabilidad. El poder del conocimiento tecnocientífico, el poder del dinero, el poder de las armas, el poder de las empresas y organismos multinacionales, el poder de la ambición, el poder de los medios de comunicación, toda esta realidad nos indica que hemos acumulado mucho poder, el cual marca diferencias de diferente tipo. El encanto y la soberbia del poder hace que su lógica sea: "lo que puede ser hecho, debe hacerse", no importando otros factores. Si podemos modificar la vida humana, pues hay que hacerlo. Si podemos modificar los genes, entonces hay que hacerlo. Si podemos manipular más aún el mundo subatómico, hay que hacerlo. Si podemos producir mil carros al día, hay que hacerlo. Si podemos hacer más perfectas las armas de destrucción masiva, hay que hacerlo. Sin embargo, el dinamismo del poder oculta el querer, el deseo que mueve el poder. Por lo que debiéramos preguntarnos sobre las estimaciones o deseos que busca realizar el poder. El deseo genera el poder y el poder afirma el deseo, ambos dependiendo mutuamente. $\mathrm{Y}$ a su vez el mero deseo es un proceso cultural condicionado por los ideales de una determinada época. Y ese conjunto biológico, sociocultural y psicológico siempre en movimiento es lo que subyace a los problemas que enfrentamos con respecto al desborde del poder en nuestra época.

Es esta lógica que subordina el deber al poder la que hace peligrosa la acumulación del poder ${ }^{11}$. Todo ello hace necesario relacionar el poder con la responsabilidad. Uno de los que ha pensado esta relación ha sido Jonas. Nos dice:

la responsabilidad es un correlato del poder, de tal modo que la clase y la magnitud del poder determinan la clase y la magnitud de la responsabilidad. Cuando el poder y su ejercicio alcanzan ciertas dimensiones, no sólo cambia la magnitud de la responsabilidad, sino que también se produce un cambio cualitativo en su naturaleza, de modo que los actos del poder producen el contenido del deber; éste es, esencialmente, por lo tanto, una respuesta a lo que acontece... Nosotros tenemos que decir hoy: debes, puesto que haces,

\footnotetext{
11 Obviamente el poder, por ejemplo biotecnológico, está asociado a fines propuestos por otros poderes, como el económico, político o militar. Así la pregunta es por qué tipo de fines está siendo guiado el poder en sus diversos aspectos. Y la otra cuestión es cómo pueden asumir sus responsabilidades los sujetos poseedores de tales poderes.
} 
puesto que puedes; es decir, tu enorme poder está ya en acción (Jonas, 1995: 212).

Hemos acumulado tal poder que su ejercicio necesita más de la ética en nuestros días. Lo que no significa imposición de verdades absolutas, sino la necesidad de un debate público que no vulnere derechos fundamentales de las personas. Sin una madurez ética las posibilidades de usar correctamente el poder se reducen. Más aún, ni siquiera nos percatamos que tenemos poder y que requiere de un uso prudente. Ese es el caso de los celulares, que nos dan el poder de comunicación, pero se los damos a nuestros niños cuando los médicos están diciendo que sería prudente que los niños no los usen, por posibles efectos negativos a su salud física y mental. En un contexto mayor, países que contaminan el medioambiente no se sienten responsables ni son responsables, al no firmar tratados internacionales como el Protocolo de Kyoto. Una simple lógica ética nos dice que a mayor poder, mayor responsabilidad, pero no siempre se cumple esta enseñanza ética básica.

¿Puede haber mayor y menor responsabilidad? En la medida que formamos parte de esta humanidad y somos expresión de ella, somos responsables de la condición cultural, material, moral o ecológica de nuestra sociedad. Sin embargo, las autoridades públicas y privadas, los dueños de corporaciones, los países industrializados, tienen mayor responsabilidad, tanto por los deberes que tienen como por los impactos de sus acciones. Lo mismo puede decirse con respecto a las guerras. Quien tiene más poder tiene mayor responsabilidad, por lo que debe responder ante los demás sobre sus pretensiones, acciones y consecuencias. Y esto no nos exonera de responsabilidad, pues en la medida que sigan existiendo las guerras es responsabilidad de todos nosotros no fomentarla y hacer algo para oponerse a ellas.

\section{6. ¿NECESITO COMPROMISOS PARA SER RESPONSABLE?}

$\mathrm{Al}$ realizarse nuestras actividades con otros y dentro de instituciones, asumimos ciertos compromisos y por ellos somos responsables. El gerente de una empresa está identificado, comprometido con la institución y desde ahí toma decisiones que tienen consecuencias y por las que debe responder. Sin embargo, de un modo más radical, ha sido Levinas quien ha visto que antes de mi libertad, de mi compromiso y de mis decisiones, es en el encuetro con el otro donde empieza mi responsabilidad. Ha afirmado: 
La libertad del otro jamás podría comenzar en la mía, esto es, asentarse en el mismo presente, ser contemporánea, serme representable. La responsabilidad para con el otro no puede haber comenzado en mi compromiso, en mi decisión. La responsabilidad ilimitada en que me hallo viene de fuera de mi libertad, de algo "anterior-a-todo-recuerdo", de algo "ulterior-a-todo-cumplimiento", de algo no-presente; viene de lo no-original por excelencia, de lo an-árquico, de algo que está más acá o más allá de la esencia. La responsabilidad para con el otro es el lugar en que se coloca el no-lugar de la subjetividad, allí donde se pierde el privilegio de la pregunta dónde (Levinas, 1987: 54).

No somos responsables solo porque estamos comprometidos con algo o hayamos tomado decisiones personales que afectan la vida de otros, lo cual es colocar la responsabilidad en la subjetividad. La responsabilidad "viene de fuera de mi libertad" $" 12$, viene de la presencia del otro que al mostrarse como pobre, excluido o explotado, como ser vulnerable, me llama a la respuesta. El otro es el punto de partida de mi responsabilidad, por eso es "anterior-a-todo-recuerdo" (no soy responsable porque conozca a alguien, porque sea amigo, pariente o compatriota) y "ulterior-a-todocumplimiento" (no soy responsable porque sea un sujeto que cumple con sus deberes). Responsabilidad que viene de lo no original, de lo que se muestra cotidianamente, pero que mi mirada evita para no sentirse amenazado. Por lo que la responsabilidad no se encuentra en la esencia humana, sino en la vida de los hombres, sus relaciones, sus encuentros y desencuentros.

En otras palabras, desde un aspecto superficial, la responsabilidad se debe a mis compromisos pactados explícita o implícitamente, lo que se expresa a través de costumbres o de normas establecidas. Dependerá de mi libertad si respondo o no a esas exigencias. Pero una responsabilidad más radical, ética, nos dice que la responsabilidad no empieza con mi libertad sino con la presencia del otro, cuya presencia me convoca a actuar, a responder. Esto se muestra en toda su crudeza — más radicalmente humana- con respecto a los seres humanos que sufren, por la pobreza y la exclusión a que son condenados por el sistema. En ambos casos, la vulnerabilidad humana se presenta como llamado a la responsabilidad. En una vida atenta hay compromisos vitales, no solo formales o ideológicos.

12 Más adelante vuelve a decir: "La paradoja de esta responsabilidad consiste en el hecho de que estoy obligado sin que tal obligación haya comenzado en mí" (Levinas, 1987: 57). No es mi yo quien decide estar obligado ni tampoco sentirse responsable. Ambos empiezan fuera de mí. 


\section{7. ¿PUEDE HABER RESPONSABILIDAD SIN CULPA?}

Como hemos dicho, para ser responsable se le debe imputar a alguien una acción, es decir, alguien debe ser culpable de dicha acción. Si estoy ebrio y tomo un arma y agredo a una persona, soy responsable de lo que hice porque soy el culpable. Hay un actor que hace las cosas voluntariamente ${ }^{13}$ y debe responder por lo que hace. Como dice Camps: "La responsabilidad y la culpa son dos conceptos que se dan la mano: uno se siente responsable de haber hecho algo que no era adecuado, que no debía hacerse, algo anormal, imprevisto o fuera de lugar" (1990: 61).

Pero, ¿podemos ser responsables por acciones o situaciones de las que no tenemos culpa? ¿Quién es culpable por la crisis medioambiental? ¿Quién es culpable del calentamiento global y la destrucción de la capa de ozono? ¿Quién es responsable por la hambruna en África? ¿Somos responsables del mundo que dejaremos a las generaciones futuras? Camps dice acertadamente que en esas situaciones no deberíamos preguntarnos "¿qué he hecho yo para que esto ocurra?", sino preguntarnos "¿qué he hecho o qué estoy haciendo para que no ocurra?” (Camps, 1990: 71). Sin anular las culpas, también hay responsabilidad que deben asumir los que no tienen culpa: ¿qué hacemos para que esto no ocurra? Quizá no hayamos ocasionado la hambruna ni la tuberculosis de poblaciones enteras, ni el calentamiento global, pero ¿qué estoy haciendo para que eso no ocurra? Somos éticamente responsables del futuro, de que las cosas puedan cambiar en algo, de hacer un mundo mejor. Como pensaba Jonas, la responsabilidad es expresión de nuestro ser temporal, por lo que no solo somos responsables del pasado (por lo que no he hecho), sino por el futuro (por lo que haré para que una situación cambie). Aspecto relevante cuando se trata de pensar sobre el mundo que dejaremos a las generaciones futuras. Pero ambos, pasado y futuro dependen de este presente, por eso se hace relevante una ética de la atención, del cuidado del mundo que vivimos ${ }^{14}$ (Polo, 2016). Relacionar responsabilidad y culpa solo es ver parte de este complejo fenómeno moral, pues se hacen relevantes las consecuencias que son sentidas ("me siento culpable"), aunque puede ser pensada la culpa

13 Previamente el sujeto sabe que en estado de ebriedad las personas se desinhiben y pueden realizar cualquier tipo de acción imprudente. Más aún, el sujeto sabe los efectos que produce en él el estado de ebriedad. Por lo que habría doble responsabilidad.

14 Quedarnos en el pasado o solo ver el futuro necesitaría una responsabilidad moral que solo pide a los sujetos que asuman las consecuencias de sus actos o dice que los sujetos debemos cumplir con sus obligaciones morales o legales. La vida atenta es por el presente, sin el cual no podemos dar cuenta del pasado ni hacernos cargos del futuro. Así, una ética sostenida en la atención y el cuidado sería la forma de responsabilidad ética ante el presente. 
como un darse cuenta tardío, por lo que nos llama a pedir perdón y reparar el daño causado.

\section{8. ¿UNA ÉTICA MUNDIAL EXIGE UNA RESPONSABILIDAD MUNDIAL?}

Debido a la globalización económica, pero también a la universalización de redes de comunicación, algunos autores hablan de la posibilidad de una ética mundial o una ética plantearía. ¿No es esto una pretensión universalista más que olvida la diversidad cultural y sociales reales?

Hemos considerado que la libertad, primariamente, no es "yo quiero" (despliegue de mi subjetividad), sino es un dejar ser a lo que es (perspectiva ontológica), lo que nos pide disposición para contemplar, para ver y actuar (perspectiva ética). No podemos dejar de ser responsables porque la vida es relación con lo que es. Y lo que es reúne tanto el pasado como el futuro, ambos reunidos en este presente vivo. Por eso hemos dicho que nuestra responsabilidad con el presente incluye también nuestra responsabilidad con pasado y el futuro, con el hermano que sufre como por las generaciones futuras.

Una de las formas que toma la ética planetaria, y con ella la responsabilidad planetaria, es nuestra preocupación por el futuro de la humanidad. Una vez más, ha sido Jonas quien ha propuesto una ética de la responsabilidad teniendo en cuenta nuestro futuro. Este pensador alemán, buscando un nuevo imperativo que responda a los nuevos tiempos, formula el siguiente: "Obra de tal modo que los efectos de tu acción sean compatibles con la permanencia de la vida humana auténtica en la Tierra” (Jonas, 1995: 40). Variantes del mismo imperativo serían los siguientes:

"Obra de tal modo que los efectos de tu acción no sean destructivos para la posibilidad futura de esa vida”.

"No pongas en peligro las condiciones de la continuidad indefinida de la humanidad en la Tierra".

"Incluye en tu elección presente, como objeto también de tu querer, la futura integridad del hombre" (Jonas, 1995: 40).

Jonas es uno de los primeros que ha tenido en cuenta a las generaciones futuras en la reflexión moral, ante el peligro de la técnica moderna que no las toma en cuenta. Los imperativos de Jonas están dirigidos especialmente a la política - aunque no solo a ella- a actuar no pensando solo en parámetros ideológicos, privados o locales, sino a tener en cuenta la continuidad de la existencia de la vida humana. Pero no de cualquier forma de existencia, sino de una vida humana digna. Sus imperativos son un llamado a repensar nuestras acciones, cuya fuente ya no puede ser la subjetividad 
personal o grupal, sino un referente externo, la vida de los seres humanos. Pero ese salto universal pasa por la percepción de la vida de los seres humanos que sufren, que viven agonizando por el olvido o explotación de los mecanismos de poder. Eso implica darle sensibilidad a la universalidad del imperativo de Jonas.

Una responsabilidad por la humanidad presente y futura, que cuestiona la cultura moderna y sus formas de vida egocéntricas y consumistas. Como hemos dicho, el poder tecnológico tiene una potencialidad destructiva, por lo que requiere repensarse la responsabilidad del poder que hemos acumulado. Y el asunto no es simplemente que estamos dañando el medioambiente, sino que está en juego la existencia de la misma especie humana. Pensemos en la tala indiscriminada de árboles que se realiza en la Amazonía, especialmente a cargo de empresas ilegales, cuya ambición afecta a las comunidades amazónicas, al medio ambiente y a la humanidad en general. La pregunta que deberían hacerse los poderes fácticos es: “ ¿Mi acción (u omisión) está permitiendo la continuidad de la vida de la humanidad en condiciones dignas?". Y desde esa pregunta elaborar mecanismos e indicadores para medir el impacto negativo de la acción, sea en investigación científica, explotación de recursos naturales o ingeniería genética. Dependiendo de ellos evaluar si una acción es social y humanamente responsable.

Los retos actuales son enormes: la contaminación del medio ambiente, la depredación de la biodiversidad, el calentamiento global, la superpoblación, la pobreza, la guerra, etc. Todos ellos llamando a la responsabilidad de los políticos, empresarios, profesionales y ciudadanos en general, al cuidado de la continuidad de la vida humana presente y futura. Y ese actuar responsable no puede esperar reciprocidad, como también lo afirma Jonas y Levinas, por lo que debe presentar su faceta genuinamente ética, es decir, desinteresada.

Y como bien lo sabía Jonas, los deberes no pueden sostenerse en sí mismos, sino en una nueva sensibilidad. $Y$ eso ya nos genera una nueva interrogante: ¿cómo surge esa nueva sensibilidad? ¿Es posible educarla? Intentaremos una respuesta más adelante.

\section{9. ¿PUEDEN LAS INSTITUCIONES AYUDARNOS A SER RESPONSABLES?}

Como las actividades sociales (colectivas, comunitarias) se producen dentro de instituciones, tenemos que incluirlas dentro del tema de la responsabilidad, dado que estas influyen directamente en la conducta de las personas. Más aún, nos abren nuevos aspectos de la responsabilidad (responsabilidad profesional, responsabilidad empresarial, etc.), pero también pensar los conflictos de los sujetos que las integran (por ejemplo, ser fieles 
a una práctica religiosa dentro de instituciones determinadas). Una institución puede favorecer a las prácticas responsables o puede promover lo contrario, por lo que los mecanismos que esta elabore para dar respuestas por lo que hacen tienden a promover una cultura responsable en la vida de los sujetos que las integran.

Etxeberria (2002) nos dice que con el marco institucional aparecen tres nuevos elementos importantes para la responsabilidad: a) Las organizaciones pueden coaccionar la iniciativa personal, especialmente cuando los sujetos tienen otras creencias y normas de conducta. Lo que cabe aquí es el discernimiento entre la política institucional y nuestras opciones morales; b) la corresponsabilidad de los integrantes que puede o diluir la responsabilidad personal ("todos son culpables") o exacerbar la responsabilidad personal ("sólo el director o gerente es responsable"); c) "específicas y variadas conexiones, según los casos, con la dinámica política de la sociedad" (Etxeberria, 2002: 180). Esta red de relaciones puede favorecer las buenas o malas prácticas, aunque siempre debe pasar por las decisiones responsables de las personas, después de todo no estamos determinados por las instituciones.

Hemos colocado a las organizaciones dentro de la responsabilidad social porque estas están compuestas por ciudadanos y comunidades profesionales. Las corporaciones no pueden esconder su cara humana (sea social o personal), por más grandes que sean. Así, una minera que contamina los ríos, que son fuentes de subsistencia de comunidades campesinas, sus miembros son responsables moralmente de lo que hacen, aunque el grado de responsabilidad moral y jurídica recaiga sobre unos gerentes o propietarios. El rostro frío de las corporaciones son solo máscaras, porque dentro de ellas hay personas, seres humanos que actúan y deben responder por sus acciones y decisiones ${ }^{15}$.

En síntesis, las actividades de las personas, por lo general, se realizan dentro de grupos humanos, colectividades o comunidades con historias. Buena parte de las actividades humanas sociales se realizan dentro de instituciones. De ese modo, la responsabilidad no es solo personal sino también colectiva e institucional, en una doble dirección. Somos responsables de las instituciones, pero también las instituciones favorecen o no a que las personas sean responsables. Las instituciones tienen hábitos de trabajos, normas consuetudinarias, que influyen positiva o negativamente en los

15 A veces se piensa que en las grandes corporaciones multinacionales no cabe responsabilidad, pero creo que es hacer un fetiche de una institución, es decir, de verla como objeto de poder, sin pensar en las personas que las sostienen. Semejante al poder que tenían los ídolos de las religiones primitivas cuyo poder encubría las acciones de los sacerdotes y por -y para- los ídolos se podían justificar sacrificios humanos. 
trabajadores. Pensemos en una empresa que suele dar coimas a funcionarios estatales para realizar sus negocios. Y si esa empresa mueve negocios millonarios y paga bien a sus trabajadores, estos se sentirán propensos a seguir las malas prácticas de la empresa, con el fin de mantener sus puestos laborales, no importando el impacto en la sociedad ni si va contra las leyes del libre mercado (que idealmente afirma la simetría de los que participan en el mercado).

\section{0. ¿EN QUÉ CONSISTE LA RESPONSABILIDAD DEL POLÍTICO?}

En la conferencia “La política como vocación”, Max Weber (1972) trazó una distinción que ha quedado como clásica, entre éticas de la convicción (Gesinnungsethik) y éticas de la responsabilidad (Verantwortungsethik), para darle lugar a la ética en la actividad política. La "ética de la convicción" es aquella donde las personas asumen creencias y principios de vida determinados y viven en base a ellas. Podemos poner como ejemplos las convicciones religiosas o las ideologías políticas o las propuestas de vida buena, donde sus miembros asumen ideas y valores y viven según ellos. Mientras la "ética de las consecuencias", es la que es propiamente la que debe practicar el político, teniendo en cuenta las consecuencias de las acciones y dar cuenta de ellas (Weber, 1972: 163-164). El propio Weber no las considera absolutamente opuestas, "sino elementos complementarios que han de concurrir para formar al hombre auténtico, al hombre que puede tener «vocación política»" (1972: 176). El hombre verdaderamente político, "maduro" como lo llama el pensador alemán, no es aquel que hace todo por lograr principios no importando sus consecuencias, sino aquel "que siente realmente y con toda su alma esta responsabilidad por las consecuencias" (1972: 176) y sabe detenerse hasta un cierto punto ("no puedo hacer otra cosa, aquí me detengo"), lo que significaría que tampoco valdría cualquier cosa para el político, porque no podría ir contra sus principios últimos $^{16}$. Después de todo, el político viviría una tensión entre ambas éticas.

Supongamos que un hombre religioso asume el gobierno, no se trata que renuncie a sus convicciones personales, sino que debe tener en cuenta las consecuencias de sus acciones, especialmente hoy que vivimos en un contexto plural. Y es que el político no busca la "salvación de su alma" a

\footnotetext{
16 Aquí Camps ve un problema, porque la posición de Weber mantendría el divorcio entre ética y política, El "aquí me detengo" implicaría al final: "O uno es político y abandona los principios y las convicciones, o si insiste en mantenerlos, no tendrá más remedio que renunciar a la política" (1995: 106).
} 
través de la política, como sí lo hace el hombre de una ética de convicciones. Más aún, el político asume la complejidad y problematicidad del campo político, y según sea el caso tendrá que responder. No es pues una ética para santos, sino una ética que debe estar acompañada de pasión y mesura, de prudencia.

Camps considera que en el planteamiento de Weber la distinción entre dos tipos de ética es "excesivamente radical". A ambas éticas le hace observaciones a tener en cuenta. A la "ética de la convicción" dice que sería difícil pensar que alguien que mantiene sus principios a toda costa esté asumiendo una actitud ética. Eso parecería ser una actitud dogmática pues "sólo pueden mantenerse públicamente a costa del terror" (Camps, 1995: 106). Además, podríamos añadir, un hombre convencido de sus principios no puede olvidar las consecuencias de sus acciones, aunque estas sean medidas por sus principios.

Con respeto a la "ética de la responsabilidad", Camps está de acuerdo con que la acción política debe ser juzgada por las consecuencias, pero ¿qué consecuencias? ¿Cómo valorar las consecuencias? Lo que pide Camps son los criterios para que una consecuencia sea ética ${ }^{17}$, de lo contrario quedaría en la vaguedad la idea de "ética de las consecuencias". Un político puede medir las consecuencias por la seguridad, el orden o el poder, sin embargo, ¿llamaríamos éticas a esas consecuencias? Y tratando de poner esos criterios éticos señala:

Si las consecuencias, en cambio, se miden con el criterio de los bienes básicos o los derechos fundamentales, la atención a las consecuencias merece plenamente el nombre de "ética" en el mejor sentido del término... La dignidad de la acción no radica en los principios o en las consecuencias, sino en el valor real de ambos (Camps, 1995: 107).

No le falta razón, porque un político que solo mide las consecuencias por la seguridad ${ }^{18}$ y el orden, pensado en las sociedades democráticas, no se distinguirían de gobiernos totalitarios de cualquier color. Este tipo de mentalidad política solo llevaría a la supresión de las libertades y al terror. ¿Cómo medir la eficacia de la gestión política? Pues no nos queda otra que

17 De la misma idea es Spaemann. "No se trata de convicción o responsabilidad, ni de considerar o no las consecuencias, sino de la cuestión: de qué consecuencias se trata y hasta qué consecuencias se extiende la responsabilidad de una acción" (1995: 75)

18 El terrorismo crea situaciones donde la idea de seguridad se vuelve obsesiva, creando así climas de terror, donde los gobiernos limitan derechos fundamentales para lograr la ansiada "seguridad". De ese modo, mientras defiende algún valor, ya se transforma en ética de la convicción. Por eso, no le falta razón a Spaemann cuando sostiene: "Una ética radical de responsabilidad en el sentido de Max Weber no es en realidad otra cosa que una ética radical de la convicción” (1995: 77-78). 
incluir criterios éticos claros y ser prudentes en la acción, porque lo que está en juego en la acción política son bienes sociales, que nos interesan a todos los ciudadanos.

\section{UNA CONCLUSIÓN PARA SEGUIR PENSANDO}

La forma tradicional de entender la responsabilidad resulta insuficiente para responder a los problemas y retos que afrontamos en nuestra época, generando su contraparte, más irresponsabilidades. Esta concepción tradicional de responsabilidad está caracterizada por dos componentes, un dar cuenta o responder según los contenidos mentales que tengamos (ideologías, creencias, historias, tradiciones, etc.), los que generan sentimientos de obligación. Así, mi creencia y sus compromisos (que asumimos como sagrados, divinos, perfectos) me hacen sentir obligado y actúo según ellos, de esa forma soy responsable. El otro componente es la autoridad que vela por el cumplimiento de las obligaciones y ante la cual debo responder (Dios, juez, padre, sociedad, otro, mi propio “yo"). Actúo según el deber porque lo dice la autoridad y no quiero recibir la sanción. Pero en una cultura individualista, la autoridad resulta siendo sospechosa de atentar contra la libertad del individuo, por lo tanto, constantemente deslegitimada. Eso hace que la libertad resulte reñida con la responsabilidad, a pesar de que en los manuales se repitan que sin libertad no hay responsabilidad. En este tipo de responsabilidad se encuentra la "responsabilidad jurídica", cuando las normas y los sancionadores ya están establecidos; pero también se encuentra ahí la responsabilidad moral, cuando se trata del compromiso ante normas (sustentadas en creencias y valores). Esta última responsabilidad señala el "debería" ideal de nuestras relaciones, pero esconde la autoridad (Dios, la sociedad o uno mismo). La experiencia humana nos ha hecho ver que estás responsabilidades son limitadas, porque carecen de algo más básico, que las relaciones naturales nos han enseñado: el cuidado, atención cuidadosa, que la ideología y la norma dejan de lado.

Por lo anterior, nuestra idea de responsabilidad subyace en otro fundamento. El dar respuesta o responder está sustentado en la mirada atenta, en la atención de lo que hacemos, del mundo y de nuestros contenidos mentales. Estos últimos no son simples hilos que dirigen al actor, sino son puestas bajo la mirada atenta (porque ya sabemos que muchas desgracias se han cometido por ideas de distinta naturaleza, hasta por ideales morales). La mirada atenta hace que la obligación se sienta de otra manera, no como presión o constricción, sino en un sentido más básico, como respuesta a causa de sentirse ligado, relacionado. Así, podemos asociar responsabilidad con obligación, pero por el hecho de estar ligados, relacionados a un mundo y a otros. Parafraseando la filosofía de Heidegger (1974), 
somos responsables debido a que somos "seres-en-el-mundo" y "serescon-otros", es decir, somos seres cuya "esencia" es relación. La conciencia de lo que entra en esa relación es lo que se ha ido ampliando a través del tiempo.

Si nos sentimos relacionados, entonces respondemos, actuamos en conformidad. Pierden peso psicológico y filosófico los contenidos mentales y la autoridad (lo cual no quiere decir que dejen de existir socialmente) y pasa a tener relevancia una vida atenta que nos permite una nueva actitud, la actitud de cuidado. Ahí está el sentido diferente de la responsabilidad: cuidar del mundo, de sí mismo y de los otros. Así, podemos afirmar que, en nuestro tiempo, una ética de la responsabilidad es una ética del cuidado, un cuidado de sí, de nuestras relaciones, del mundo y de la naturaleza. Es en esta responsabilidad, en la que deberían subyacer las responsabilidades jurídicas y morales para darles sentido y sustento, la que hemos llamado "responsabilidad ética." Quizá no sea la solución de todos los problemas, pero sí podrá devolverle al ciudadano un sentido humano más práctico y vital a su existencia.

\section{REFERENCIAS}

Bilbeny, N. (2012). Ética. Barcelona: Ariel.

Camps, V. (1990). Virtudes públicas. Madrid: Espasa-Calpe.

Camps, V. (1995). Ética, retórica, politica. Barcelona: Alianza Universidad.

Etxeberria, X. (2002). Temas básicos de ética. Bilbao: Desclée de Brouwer.

Frankena, W. K. (1965). Ética. México: UTEHA.

Gracia, D. (2011). "Ética de la responsabilidad", conferencia ofrecida en Lima, en el marco de la III Jornada Internacional de Bioética Clínica, el 19 de octubre, organizado por el Colegio Médico del Perú.

Heidegger, M. (1974). Ser, verdad y fundamento. En ¿Qué es metafísica? Y otros ensayos. Buenos Aires: Siglo XX.

Jonas, H. (1995). El principio de responsabilidad. Barcelona: Herder.

Levinas, E. (1987). De otro modo que ser, o más allá de la esencia. Salamanca: Sígueme. Lipovetsky, G. (2005). El crepúsculo del deber. Barcelona: Anagrama.

Polo, M. (2016). El silencio del Rey Mono. Autoconocimiento y ética. Lima: UNMSM.

Rifkin, J. (2010). La civilización empática. Barcelona: Paidós.

Spaemann, R. (1995). Ética: cuestiones fundamentales. Navarra: EUNSA.

Weber, M. (1972). El politico y el científico. Madrid: Alianza Editorial.

Sumario: Introducción; 1. ¿Qué significa "responsabilidad”?; 2. ¿En virtud de qué somos responsables?; 3. ¿Ante quién somos responsables?; 4. ¿De qué somos responsables?; 5. ¿El poder necesita de la responsabilidad?; 6. ¿Necesito compromisos para ser responsable?; 7. ¿Puede haber responsabilidad sin culpa?; 8. ¿Una ética mundial exige una responsabilidad mundial?; 9. ¿Pueden las instituciones 
ayudarnos a ser responsables?; 10. ¿En qué consiste la responsabilidad del político?; 11. Una conclusión para seguir pensando; Referencias. 